\title{
ESTRATEGIAS DE ELIMINACIÓN DEL SARAMPIÓN EN EL MUNDO
}

\section{Jean-Marc Olivé.}

Departamento de Vacunas y otros Biológicos. Programa Ampliado de Inmunizaciones. Organización Mundial de la Salud.

\section{INTRODUCCIÓN}

En 1989 la Asamblea Mundial de la Salud adoptó el objetivo de reducir la mortalidad y morbilidad asociada con el sarampión en $95 \%$ y $90 \%$ respectivamente, comparando con las cifras estimadas antes de la introducción de la vacuna. En 1990, la Cumbre Mundial por los Niños adoptó el objetivo de vacunar contra el sarampión al $90 \%$ de los niños para el año 2000.

Enormes progresos se han observado con relación a los objetivos de control del sarampión a escala mundial. Sin embargo, a pesar de la disponibilidad de una vacuna segura y efectiva contra el sarampión, esta enfermedad continua siendo una de las causas más importantes de morbilidad y mortalidad en los países en vías de desarrollo. Se estima que cada año, cerca de un millón de muertes debidas al sarampión ocurren a escala mundial, todas ellas en países en vías en desarro1lo, la mitad de ellas en África. Estudios sobre las mayores causas de mortalidad indican que el sarampión es la octava causa de mortalidad a escala mundial.

Este documento resume cuales son los desafíos más importantes que deben superarse para alcanzar los objetivos establecidos para el control y eliminación del sarampión en el siglo XXI.

\section{DESAFÍOS}

Los progresos recientes con la erradicación de la poliomielitis a escala mundial han resultado de un interés creciente en el control del sarampión. Cuando el objetivo de la erradicación de la poliomielitis fue establecido por la Asamblea Mundial de la Salud en 1988, la poliomielitis era endémica en la mayoría de los continentes y cerca de 35.000 casos de poliomielitis eran informados cada año. En 1998, el número de casos de poliomielitis descendió a 3.000. Los sistemas de vigilancia epidemiológica intensificada de las parálisis flácidas agudas indican que la transmisión del poliovirus salvaje ha quedado reducida a sólo algunos países, principalmente en África y Asia. La implementación adecuada de las estrategias de vacunación en los últimos reservorios del virus de la polio se constituyó en un reto para los años venideros.

El primer desafio para acelerar el control del sarampión consiste en consolidar los logros en materia de erradicación de la poliomielitis y asegurar que los esfuerzos apoyan y no debilitan la prioridad necesaria en las ultimas fases del programa de erradicación de la polio. En los países donde la polio continua siendo endémica, los esfuerzos deben concentrarse en el control del sarampión y la reducción de la mortalidad. Los objetivos de eliminación del sarampión deben ser establecidos solamente en aquellas regiones 
donde la circulación del poliovirus salvaje ha sido interrumpida.

En 1997, fueron informados 702.298 casos de sarampión a la Organización Mundial de la Salud (OMS). Esta cifra representa una reducción del $48 \%$ comparada con el número de casos notificados en 1990. Entre las seis regiones de la OMS, la Región Africana notifica la incidencia más alta del sarampión (47,5 por 100.000), y la Región de las Américas informó la más baja incidencia ( 6,5 por 100.000). Es importante hacer notar que los 51.915 casos del sarampión informados en la Región de las Américas en 1997, representan un incremento de 25 veces cuando se comparan con los 2.109 casos notificados en 1996, año en el que se informó la cifra más baja de casos en esa región. El aumento es el resultado de un brote de sarampión con mas de 42.000 casos confirmados en el estado de Sao Paulo, Brasil, que se extendió a otros estados en el Brasil y a otros países de la región.

La cobertura de vacunación antisarampionosa en niños menores de un año, a escala mundial, alcanzó el $80 \%$ en 1990 y se ha mantenido en este nivel desde entonces. Los progresos en la cobertura de vacunación antisarampionosa varían entre las diferentes regiones del mundo. En 1997, 21\% (10/48) de los países en la región de África notificaron una cobertura de vacunación contra el sarampión inferior al 50\%.

El segundo desafío consiste en acelerar los esfuerzos para controlar el sarampión y reducir la mortalidad asociada, espccialmente en África y el Sudeste Asiático.

Para 1997, la OMS estimaba que ocurrieron, aproximadamente, 31 millones de casos de sarampión y 960.000 muertes debidas al sarampión a nivel mundial. Antes de fin de 1997, la morbilidad y la mortalidad globales debidas al sarampión habian disminuido a porcentajes de $74 \%$ y $85 \%$, respectivamente, comparados con las cifras estimadas de morbilidad y mortalidad anuales antes de la introducción de la vacuna. La Región de las Américas, La Región Europea y la Región del Pacifico Occidental alcanzaron los objetivos de la Asamblea Mundial de la Salud en relación con la reducción de la morbilidad y la mortalidad. Cuando se agrupan los países considerando su nivel de desarrollo económico, $99 \%$ de las muertes estimadas por sarampión en 1997 ocurrieron en los países menos desarrollados y en los países en desarrollo y menos del $1 \%$ de las muertes ocurrieron en países desarrollados o países en transición económica.

Campañas de vacunación en áreas de alto riesgo (por ejemplo, áreas marginales de los centros urbanos y áreas rurales con población concentrada) han sido implementadas en algunos países como una estrategia para reducir la mortalidad. En 1998, este tipo de campañas fue implementado en 10 países ( 5 en Africa y 4 en el Sudeste de Asia). Durante estas campañas, cerca de 5.8 millones de niños fueron vacunados.

Para acelerar el control del sarampión se requiere alto nivel de apoyo político a largo plazo que asegure la implementación adecuada de tres estrategias prioritarias. Primero, son requeridos esfuerzos adicionales para mejorar la cobertura global de vacunación antisarampionosa en niños menores de 1 año y para establecer la infraestructura necesaria para sostener estos niveles de cobertura. Segundo, campañas masivas de vacunación diseñadas para niños no vacunados a través del programa de vacunación de rutina son necesarias en los países en vías de desarrollo donde la mortalidad por sarampión continua siendo alta. Se requiere la vigilancia intensa del sarampión para dirigir las actividades de vacunación y monitorizar los progresos del programa.

Los objetivos regionales para la eliminación del sarampión han sido establecidos en tres de las seis regiones de la Organización Mundial de la Salud. En 1994, la Conferencia Sanitaria Panamericana estableció el objetivo de eliminación de la circulación del 
virus autóctono del sarampión en la región de las Américas para el año 2000.

Tres estrategias de vacunación han sido recomendadas para alcanzar el objetivo de eliminación del sarampión: (1) una campaña masiva de vacunación antisarampionosa, vacunando a todos los niños en los grupos de edad donde la mayoría de los sujetos susceptibles se ha acumulado (generalmente niños de 9 meses a 14 años) independientemente de su historia de vacunación, para reducir el mayor numero de susceptibles acumulado desde la introducción de la vacuna; (2) mantenimiento de coberturas de vacunación antisarampionosa por encima del $95 \%$ en menores de 1 año, para reducir la velocidad con la que nuevos susceptibles entran en la población; (3) campañas periódicas de seguimiento (cada 3-5 años), durante las cuales se inmunizan a todos los nacidos desde la campaña inicial, para prevenir la acumulación de susceptibles. Además, es necesario establecer un sistema de vigilancia epidemiológica intensificada. Todos los casos sospechosos de sarampión deben ser notificados e investigados con un sistema para la confirmación de casos a través del laboratorio. Este sistema es necesario para establecer las áreas donde la transmisión se ha restablecido y para monitorizar las cepas de virus del sarampión que están circulando.

De la misma manera, han sido establecidos los objetivos para la eliminación del sarampión en la región Europea (año 2007) y la región del Mediterráneo Oriental (año 2010). Campañas masivas de vacunación con el objetivo de interrumpir la transmisión del sarampión han sido también implementadas en los países del Sur de África.

Para el final de 1996, todos los países de la región de las Américas (con la excepción de los Estados Unidos de Norteamérica) habían implementado la campaña masiva inicial, con el propósito de interrumpir la transmisión. Durante estas campañas más del $90 \%$ de los niños de 9 meses a 14 años fue- ron vacunados, y la mayoría de los países han cumplimentado las campañas de seguimiento. Además, un sistema de vigilancia intensificada con investigación de todos los casos sospechosos de sarampión y confirmación a través del laboratorio ha sido establecido en todos los países de la región de las Américas.

Campañas similares han sido implementadas en Europa (Gran Bretaña y Rumania), el Pacifico Occidental (Mongolia, las Islas del Pacifico, Filipinas, Nueva Zelanda y Australia), el Mediterráneo Oriental (Bahrein, Jordania, Kuwait, Omán, Túnez y Siria), el Sur de África y el Sudeste Asiático (Bhutan y la Maldivas).

La adecuada cumplimentación de todas las estrategias para la eliminación del sarampión se constituye en el tercer desafío. Los esfuerzos deben asegurar especialmente que el establecimiento de vigilancia activa del sarampión acompañe las campañas masivas de vacunación y que todas las estrategias de vacunación son cumplimentadas de manera adecuada y oportuna.

Es necesario el fortalecimiento de los sistemas de vigilancia del sarampión en los países desarrollados y en vías de desarrollo y representa el cuarto desafío. La disponibilidad de información regular y completa sobre la ocurrencia y características de los casos de sarampión (edad, estado vacunal, lugar de residencia) es necesaria, no solo para identificar cambios en la epidemiología del sarampión, sino también para dirigir las actividades de inmunización y evaluar su impacto. En los países donde el objetivo del programa es la eliminación de la transmisión del virus de sarampión, la vigilancia activa se convierte aún más en un elemento critico. La vigilancia activa durante los esfuerzos de eliminación del sarampión, incluye la investigación epidemiológica y confirmación virológica de todos los casos sospechosos de sarampión. El papel del laboratorio se hace más prominente cuando la incidencia del sarampión es reducida drásti- 
camente. En estas circunstancias la confirmación de casos con base en los datos clínicos solamente se vuelve poco especifica.

El sarampión no es reconocido como una causa importante de morbilidad y mortalidad en algunos países desarrollados. Mejorar el control del sarampión en los países desarrollados y asegurar que su contribución a la morbilidad es ampliamente reconocida constituye el quinto desafío. Un ejemplo de esto, es el hecho de que el sarampión no sea una enfermedad de notificación obligatoria en un numero de países desarrollados y que las coberturas de vacunación antisarampionosa sean inferiores al $80 \%$ en áreas o la totalidad de algunos de estos países.

Los esfuerzos deben dirigirse a mejorar los sistemas de vigilancia, a documentar la frecuencia de complicaciones y mortalidad asociadas al sarampión y a motivar la implementación de estrategias de vacunación para reducir el número de personas susceptibles en estos países.

Entre 1996 y 1997 se realizaron dos reuniones mundiales de expertos para revisar toda la evidencia científica en relación con la erradicación del sarampión. Durante ambas reuniones, los expertos concluyeron que la erradicación del sarampión es técnicamente posible con la vacuna disponible y que la erradicación podría ser alcanzada en un plazo de 10 a 15 años. Además, señalaron un numero de asuntos prioritarios a los cuales se debería prestar atención de manera inmediata. Estos incluyen entre otros, alcanzar y certificar la erradicación de la poliomielitis a escala mundial y el refinamiento de las estrategias actuales para la eliminación del sarampión. Los expertos enfatizaron en la necesidad de mejorar la cobertura de vacunación antisarampionosa a través del programa de rutina como un requisito para el logro de la erradicación del virus del sarampión.

Finalmente, el sexto desafío consiste en dar respuesta a un número de preguntas aun no resueltas. Entre otras, estas preguntas in- cluyen la evaluación del impacto de campañas de vacunación en áreas de alto riesgo y la evaluación de diferentes estrategias para acelerar el control del sarampión. Métodos simples para estimar y monitorizar el número de susceptibles son requeridos, de modo que esta información apoye a los gerentes del programa de inmunización, para decidir la frecuencia y los grupos de edad que deben ser incluidos en las campañas dirigidas a interrumpir la transmisión.

Igualmente, la actual pandemia del virus de immunodeficiencia humana (VIH) ha resultado en el planteamiento de algunas preguntas relacionadas con el mejor esquema de vacunación en áreas de alta prevalencia de infección con VIH, el posible efecto de la inmunización Antisarampionosa en el curso de la infección con VIH y la posibilidad teórica de excreción prolongada del virus del sarampión en individuos con sistema inmunodeficiente.

Estudios de costo beneficio ayudaran a documentar las ganancias obtenidas a través de las diferentes estrategias recomendadas, alcanzar un mejor control de la enfermedad y los infinitos beneficios que se acumularán si es que la erradicación del virus del sarampión es alcanzada.

\section{CONCLUSIONES}

A pesar de la disponibilidad de vacunas seguras y eficaces contra el sarampión desde 1963 , todavía continua siendo la causa de aproximadamente un millón de muertes cada año. El sarampión era la octava causa de muerte a nivel mundial en 1990 . La enfermedad sigue siendo altamente endémica en varios países en Europa, Asia, y África, independientemente de nivel del desarrollo económico. Sin embargo, las muertes relacionadas con el sarampión ocurren casi exclusivamente en países menos desarrollados o en vías de desarrollo.

La cobertura rutinaria de vacunación antisarampionosa alcanzó el $80 \%$ a nivel mun- 
dial en $1990, \mathrm{y}$ ha mostrado un incremento mínimo entre 1990 y 1997. La cobertura global encubre diferencias importantes en los niveles de cobertura logrados por las seis regiones de la OMS y entre países dentro de las regiones. La Región de las Américas y la Región del Pacifico Occidental alcanzaron el objetivo de cobertura establecida por la Cumbre Mundial para los Niños; sin embargo, ambas regiones tienen países con cobertura inferior al $90 \%$.

La Región de las Américas, la Región Europea y la Región del Pacifico Occidental han comenzado la eliminación regional del sarampión y continúan haciendo progresos hacia la realización del objetivo.

La vigilancia eficaz del sarampión es crítica para vigilar el impacto de las actividades de la vacunación y adaptar políticas y estrategias. La consolidación de los sistemas de la vigilancia del sarampión se requiere en los países en desarrollo y en los paises desarrollados. La vigilancia del sarampión, que combina datos epidemiológicos y vigilancia del virus del sarampión, es necesaria cuando la incidencia de la enfermedad disminuye a niveles muy bajos como resultado de campañas masivas de vacunación intensiva. Para facilitar la vigilancia del virus del sarampión, durante una reunión mundial de expertos en virología en 1998 se estableció un sistema para mantener una nomenclatura estandarizada, para describir las características genéticas y las relaciones entre los ocho grupos de virus salvaje del sarampión que han sido caracterizados a nivel mundial.

El progreso hacia la realización de objetivos globales de la cobertura de la reducción y de la vacunación del sarampión para el 2000 , depende sobre todo del funcionamiento futuro de los programas de la vacunación. Para acelerar el control del sarampión y alcanzar los objetivos de eliminación regional, tres áreas prioritarias deben ser tenidas en cuenta. Primero, el incremento de la cobertura de vacunación antisarampionosa en niños menores de un año y la consolidación de las in- fraestructuras necesarias para sostener estos logros en la cobertura con el programa de rutina. En segundo lugar, las campañas de vacunación deben ser dirigidas a asegurar que los niños no cubiertos por servicios rutinarios de vacunación sean inmunizados. Cualquier campaña masiva de vacunación antisarampionosa en áreas de alto riesgo debe inmunizar a todos los niños en el grupo de edad seleccionado, sin importar el estado de vacunación previo o la historia de enfermedad. Tercero, en países con objetivos de eliminación del sarampión, es necesario alcanzar la cobertura más alta posible (mayor del $90 \%$ ) durante las campañas nacionales de vacunación masiva contra el sarampión y durante las campañas periódicas de seguimiento para alcanzar y mantener la interrupción del virus autóctono del sarampión.

La cumplimentación de las actividades aceleradas control/eliminación del sarampión debe facilitar y no comprometer la iniciativa global de erradicación de la poliomielitis que se encuentra en las ultimas etapas a nivel mundial. Las actividades de control del sarampión en países en los que la poliomielitis continua siendo endémica y en los países con la transmisión focal del poliovirus deben apuntar a la reducción de la morbilidad y de la mortalidad.

La eliminación del sarampión en el hemisferio occidental para el año 2000 es posible, si las estrategias de vacunación y de vigilancia del sarampión se intensifican rápidamente. En 1996 y 1997, se realizaron reuniones globales para evaluar si la erradicación mundial del sarampión es técnicamente factible. Los expertos concluyeron que la eliminación global del sarampión es técnicamente posible con las vacunas disponibles. El establecimiento de un esfuerzo global de erradicación del sarampión en los comienzos del siglo xxI requerirá que sea alcanzado el objetivo global de erradicación del poliovirus salvaje y que sean consolidados los esfuerzos de eliminación del virus autóctono del sarampión en el hemisferio occidental. 
Figura 1

Países según cobertura alcanzada con la vacuna antisarampionosa, 1997

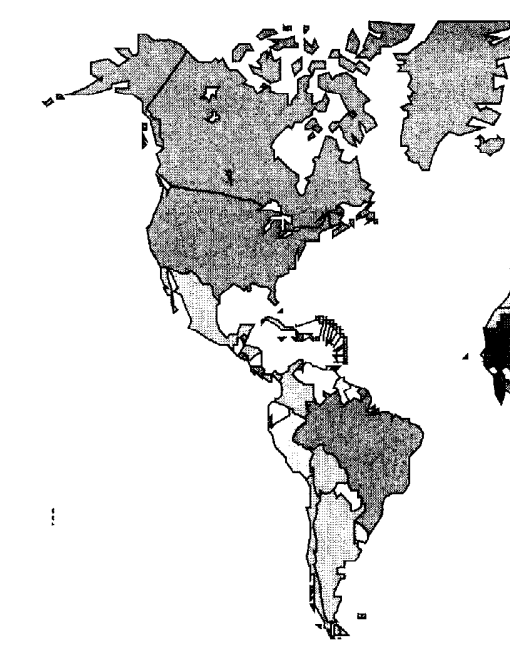

acion disponible hasta el 20 de Julio, 1997

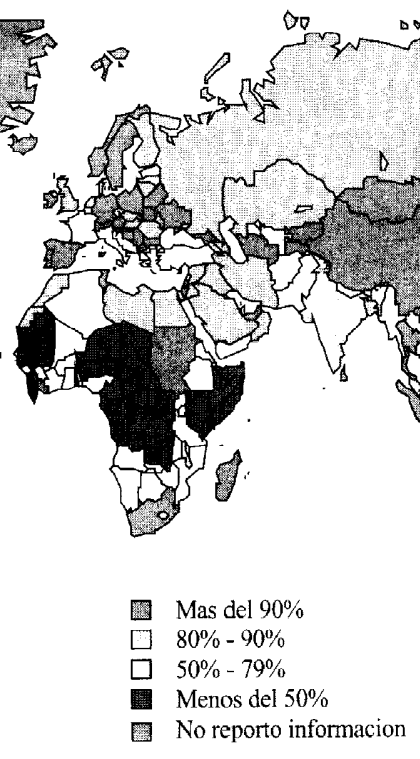

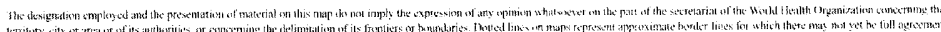

Figura 2

Países según las metas del programa de eliminación y control del sarampión, 1998

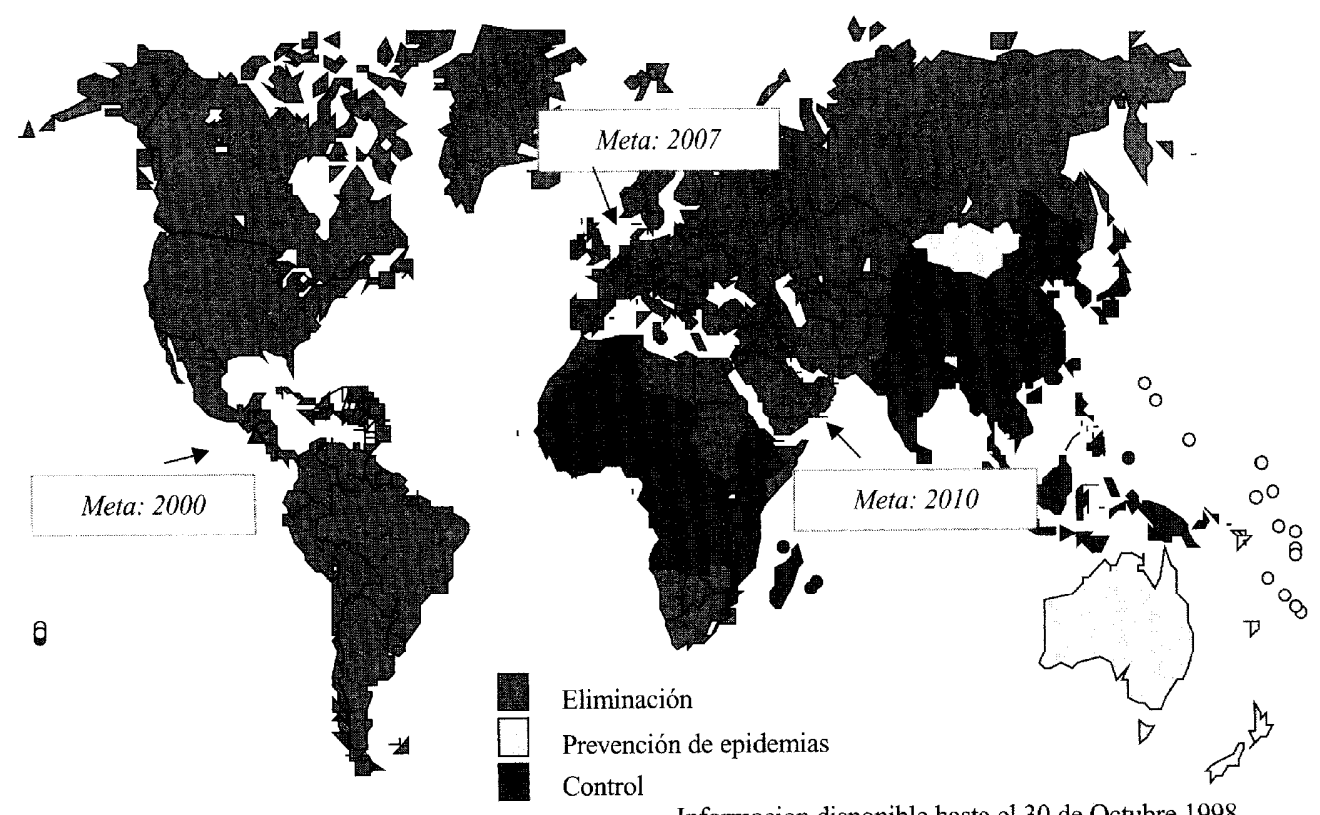

Informacion disponible hasta el 30 de Octubre 1998 
Figura 3

Cobertura con vacuna antisarampionosa en Japón y algunos países europeos, 1983-1996

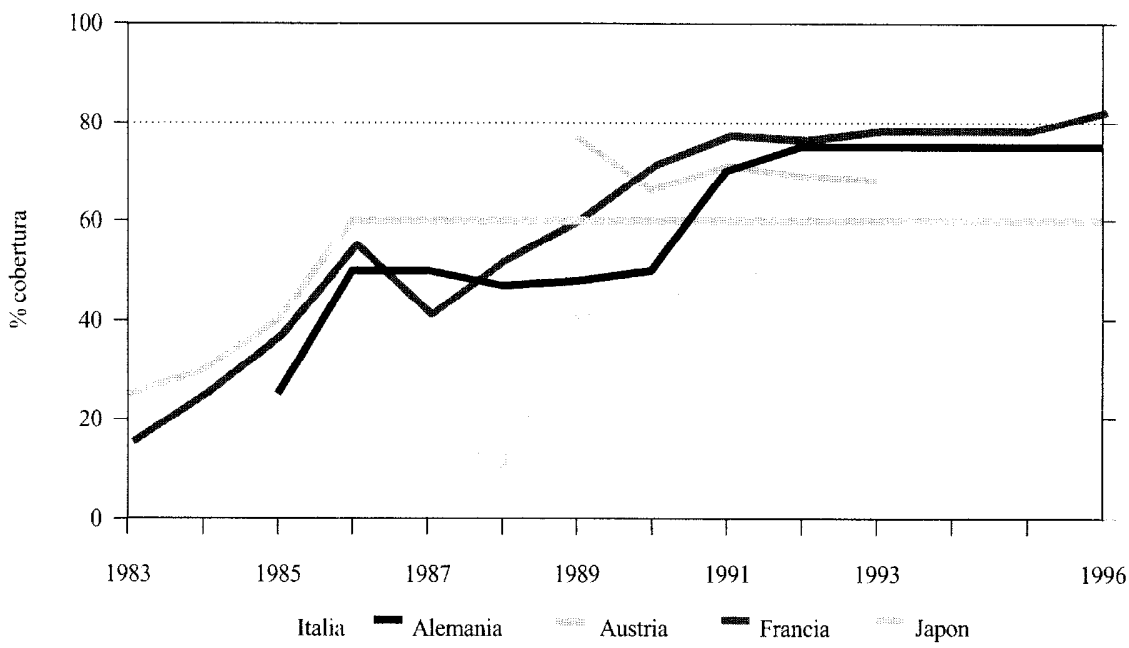

Fuentes: WHO

Tabla 1

Frecuencia de complicaciones asociadas con el sarampión en países seleccionados

\begin{tabular}{|lcccc|}
\hline & Bélgica & Francia & USA & Suiza \\
& $1982-1990$ & 1995 & 1990 & 1996 \\
\hline Número de casos & 2,289 & 124 & 27,697 & 231 \\
Complicaciones & $15 \%$ & $20 \%$ & $22.7 \%$ & $7.9 \%$ \\
Otitis Media & $7.6 \%$ & $10 \%$ & $6.6 \%$ & $3 \%$ \\
Neumoní & $4.1 \%$ & $6 \%$ & $6.5 \%$ & $2 \%$ \\
Encefalitis & & $0.8 \%$ & $0.1 \%$ & $0.5 \%$ \\
Hospitalizados & $1.6 \%$ & $2 \%$ & $21.1 \%$ & $2 \%$ \\
\hline
\end{tabular}

En Francia de 1980 a 1989, 196 casos de encefalitis post-sarampión fueron notificados. 